\title{
Case Report of Cardiac Dysarethmia Following Dental Prescription of Metronidazole
}

\author{
Al Matrafi Badria ${ }^{1 *}$, Al Rumaihi Faisal ${ }^{1}$, Al Saleem Afnan ${ }^{2}$, Al Hamad Saud ${ }^{3}$, Al Saif Sultan ${ }^{4}$ \\ ${ }^{1}$ Restorative and Consultant Restorative, Prince Sultan Military Medical City, Saudi Arabia \\ ${ }^{2}$ Consultant Pedodontic, Prince Sultan Military Medical City, Saudi Arabia \\ ${ }^{3} A G D$ Specialist, Prince Sultan Military Medical City, Saudi Arabia \\ ${ }^{4}$ Medical College, Al Maarefa Medical College, Saudi Arabia
}

"Corresponding author: Al Matrafi Badria, Consultant and Supervisor, Prince Sultan Military Medical City, Dental Sulaimania, Riyadh 11159, Saudi Arabia, Tel: +966505409808; E-mail: dr_badria@hotmail.com; azomar@psmmc.med.sa

Received date: December 29, 2016; Accepted date: January 11, 2017; Published date: January 16, 2017

Copyright: @ 2017 Badria AM, et al. This is an open-access article distributed under the terms of the Creative Commons Attribution License, which permits unrestricted use, distribution, and reproduction in any medium, provided the original author and source are credited.

\section{Abstract}

Metronidazole is nitroimidazole antibiotic medication which has a specific activity against anaerobic bacteria and protozoa. In cardiology, the QT interval represents electrical depolarization and repolarization of the ventricles. A lengthened QT interval is a marker for the potential of ventricular tachyarrhythmia. Rare cases have been reported with QT prolongation in which metronidazole antibiotic had been used. The arrythmogenic properties of metronidazole is not yet clear. This case reports a 10-year-old male child of $30 \mathrm{~kg}$ body weight with no history of any chronic illness or drug allergy came to the dental clinic with facial swelling, which was diagnosed as dental abscess. He was given oral metronidazole (500 mg 3 times/day for 5 days).

On the third day, he presented to the emergency department with palpitation, vomiting and then he collapsed. Cardiac Pulmonary Recitation (CPR) done and Electrocardiogram (ECG) showed prolonged QT corrected interval (QTc $480 \mathrm{~ms}$ ). Laboratory test including serum potassium, magnesium and liver functional tests were within normal. Metronidazole was immediately stopped and subsequently the ECG retained to normal. In Conclusion, Metronidazole can potentiat QT prolongation. Further investigation should be carried out to assess its potential effect on QT interval and subsequent lethal arrhythmias. The maximum pediatric dose should be reviewed.
\end{abstract}

Keywords: Metronidazole; Antibiotic; Case report;
Electrocardiogram; Cardiac pulmonary recitation; Dental; Anaerobic bacteria; Protozoa; Isoenzymes; Chronic illness

\section{Introduction}

Metronidazole is a nitroimidazole antibiotic medication which has specific activity against anaerobic bacteria and protozoa. It is a potent inhibitor of CYP3A4 and CYP2C9 isoenzymes. In theory. It may cause QT prolongation and Torsades de Pointes (TdP) by inhibiting the metabolism of other QT prolongation agents [1-3], whereas the effect of metronidazole alone on QT interval is not well documented [4].

QT prolongation can be acquired due to inherited long QT syndromes or due to risk factors such as bradycardia or hypokalemia [5,6], in addition to drug-drug interactions which is considered the major cause of QT prolongation [7]. Recently, many cases have been reported with QT prolongation with/without TdP, in which metronidazole antibiotic had been used. Regardless of the medical history and the indication of metronidazole therapy either alone or in combination with other drugs, ECG reverted to normal within several hours of immediate drug withdrawal [8-11]. Likewise, a case had been reported in our clinic. Accordingly, the purpose of our case report is to illustrate the potentiality of the metronidazole in QT prolongation.

\section{Case Presentation}

A 10-year-old male child of $30 \mathrm{~kg}$ body weight with no history of any chronic illness or drug allergy came to the dental clinic with facial swelling, which was diagnosed as dental abscess. He was given oral metronidazole ( $500 \mathrm{mg} 3$ times/day for 5 days). On the third day, he presented to the emergency department with palpitation, vomiting and then he collapsed. CPR was done and ECG showed prolonged QT corrected interval (QTc $480 \mathrm{~ms}$ ) (Figure 1). Physical examination and laboratory tests including serum potassium and magnesium and liver functional test were within normal. Metronidazole was immediately stopped and subsequently the ECG returned to normal. Two weeks after, the ECG has been repeated and showed QTc of $390 \mathrm{~ms}$.

\section{Discussion}

Our case was the first case in our clinic to develop prolonged QT interval after using metronidazole. Metronidazole is one of the choices to treat acute dentoalveolar abscesses [12]. It is important to mention that the pediatric dose recommended for bacterial anaerobic infection is $7.5 \mathrm{mg} / \mathrm{kg}$ orally or IV every 6 hours, however the dose that used was the maximum pediatric dose $(50 \mathrm{mg} / \mathrm{kg} /$ day orally in 3 divided doses) that usually used in treatment of amebiasis. Since our patient is not known to have any risk factors to prolong QT interval such as previous use of medication, or electrolyte imbalances, and he was confirmed that he has normal structural heart and function. He was diagnosed to have a drug induced long QT syndrome (congenital long QT 
syndrome is a genetic disorder that has to be confirmed by genetic testing) similar to one of the cases that had been reported [9].

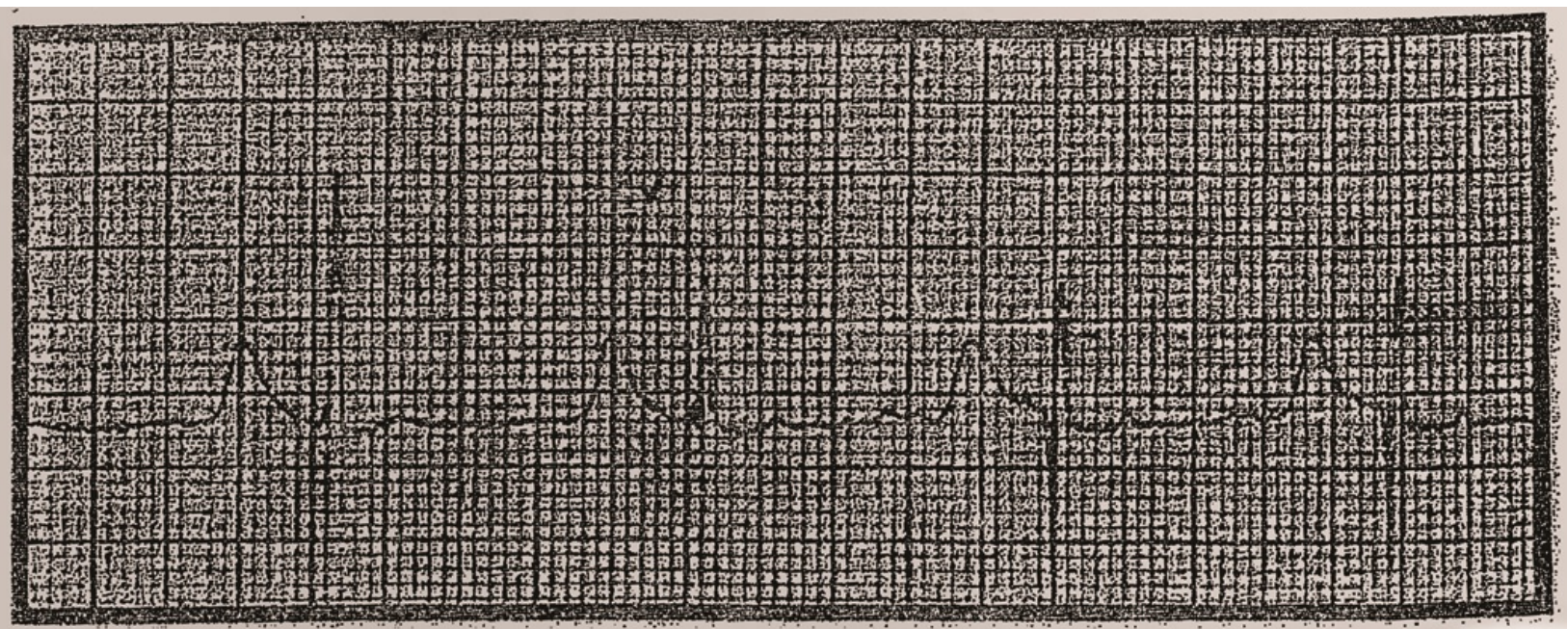

Figure 1: ECG showing prolonged QTc interval (480 ms).

Poluzzi [13] retrospectively studied 374 reports of TdP over a period of 5 years and found that two TdP cases had used metronidazole without co-medication, which in line with our case who was using metronidazole alone. Patients who are at high risk to develop QT prolongation and TdP, they are those patients exposed to drugs known to known to cause blocking of the potassium channels [14]. Therefore, metronidazole prescription should be avoided for patients at high risk for drug-induced TdP [15]. The arrythmogenic properties of metronidazole is not yet clear, and further investigation should be carried out to assess its potential effect on QT interval and subsequent lethal arrhythmias. As a final point, the maximum pediatric dose of metronidazole should be investigated.

\section{Conclusion}

Metronidazole is regarded to potentiate QT prolongation, and further investigations are needed.

\section{References}

1. Cooke C, Sklar G, Nappi JM (1996) Possible pharmacokinetic interaction with quinidine: ciprofloxacin or metronidazole? Ann Pharmacother 30: 364-366.

2. Kounas S, Letsas K, Sideris A, Efraimidis M, Kardaras F (2005) QT interval prolongation and torsades de pointes due to a coadministration of metronidazole and amiodarone. Pacing Clin Electrophysiol 28: 427-473.

3. Fehri W, Adbessalem S, Smiri Z, Mhenni H, Barakett N, et al. (2004) Short coupled variant of torsade de pointes: our experience and review of the literature. Tunis Med 82: 867-874.

4. Viskin S, Justo D, Halkin A, Zeltser D (2003) Long QT syndrome caused by noncardiac drugs. Prog Cardiovasc Dis 45: 415-427.

5. De Ponti F, Poluzzi E, Montanaro N (2010) Organizing evidence on QT prolongation and occurrence of torsades de pointes with non- antiarrhythmic drugs: a call for concensus. Eur J Clin Pharmacol 57: 185-209.

6. Roden D (1998) Taking the "idio" out of "idiosyncratic". Predicting torsades de pointes. Pacing Clin Electrophysiol 21: 1029-1034.

7. Armahizer M, Sebert A, Smithburger P, Kane-Gill S (2013) Drug-drug interactions contributing to QT Prolongation in cardiac intensive care units. J Crit Care 28: 243-249.

8. Kounas S, Letsas K, Sideris A, Efraimidis M, Kardaras F (2005) QT interval prolongation and torsades de pointes due to a coadministration of metronidazole and amiodarone. Pacing Clin Electrophysiol 28: 472-473.

9. Chohen O, Sarr N, Swartzon M, Kliuk-Ben-Bassat O, Justo D (2008) First Report of metronidazole-induced QT interval prolongation. Intr J Antimicrob Agents 31: 180-181

10. Altin C, Kanyilmaz S, Baysal S, Ozin B (2011) QT interval prolongation due to metronidazole administration. Anadolu Kardiyol Derg 11: 468-469.

11. Pandarunga P, Al-Mukhaini M, Rajarao MP (2013) Multi-factorial causes of torsade de pontes in a hospitalized surgical patient. Sultan Qaboos Univ Med J. 13: 152-155.

12. Ellison SJ (2009) The role of phenoxymethylpenicillin, amoxicillin, metronidazole and clindamycin in the management of acute dentoalveolar abscesses-a review. Br Dent J. 206: 357-362.

13. Poluzzi E, Raschi E, Motola D, Moretti U, De Ponti F (2010) Antimicrobials and the risk of torsades de pointes: the contribution from data mining of the US FDA Adverse Event Reporting System. Drug Saf. 33: 303-314.

14. Napolitano C, Schwartz PJ, Brown AM, Ronchetti E, Bianchi L, et al. (2000) Evidence for a cardiac ion channel mutation underlying druginduced QT prolongation and life-threatening arrhythmias. J Cardiovasc Electrophysiol 11: 691-696.

15. Zeltser D, Justo D, Halkin Am, Prokhorov V, Heller K (2003) Torsade de pointes due to non-cardiac drugs: most patients have easily identifiable risk factors. Medicine (Baltimore) 82: 282-290. 